\title{
An Ion Mobility/lon Trap/Photodissociation Instrument for Characterization of Ion Structure
}

\author{
Steven M. Zucker, Sunyoung Lee, Nathaniel Webber, Stephen J. Valentine, \\ James P. Reilly, David E. Clemmer
}

Department of Chemistry, Indiana University, Bloomington, IN 47405, USA

\begin{abstract}
A new instrument that combines ion mobility spectrometry (IMS) separations with tandem mass spectrometry $\left(\mathrm{MS}^{\mathrm{n}}\right)$ is described. Ion fragmentation is achieved with vacuum ultraviolet photodissociation (VUV PD) and/or collision-induced dissociation (CID). The instrument is comprised of an approximately $1 \mathrm{~m}$ long drift tube connected to a linear trap that has been interfaced to a pulsed $F_{2}$ laser $(157 \mathrm{~nm})$. Ion gates positioned in the front and the back of the primary drift region allow for mobility selection of specific ions prior to their storage in the ion trap, mass analysis, and fragmentation. The ion characterization advantages of the new instrument are demonstrated with the analysis of the isomeric trisaccharides, melezitose and raffinose. Mobility separation of precursor ions provides a means of separating the isomers and subsequent VUV PD generates unique fragments allowing them to be distinguished.
\end{abstract}

Key words: Ion mobility spectrometry, Photodissociation, Ion trap, Isomer characterization

\section{Introduction}

$\mathrm{M}$ ore than a decade ago, instrumentation was introduced that combined ion mobility spectrometry (IMS) with time-of-flight (TOF) mass spectrometry (MS), providing a means for collecting mobility information for mixtures of ions in a single experimental sequence [1]. Since that time, a number of research groups have applied this technology to the analysis of biomolecular ion structure and the characterization of complex mixtures [2-6]. Shortly after the first "nested" measurements [1], methods were developed for fragmenting mobility-dispersed precursor ions with IMS-TOF instrumentation [7-11]. IMS-MS/MS datasets offered advantages in that fragment ions could be linked directly to precursor ions because of their coincidence in drift time $\left(t_{D}\right)$. IMS-MS and IMS-MS/ MS instrumentation has been applied to the characterization of complex mixtures such as those encountered in proteomics, glycomics, and metabolomics experiments [12-19].

Steven M. Zucker and Sunyoung Lee contributed equally to this manuscript.

Correspondence to: David E. Clemmer; e-mail: clemmer@indiana.edu
A challenge for current IMS-MS instruments is the inability to identify ions of similar mobilities with the parallel collision-induced dissociation (CID) approach [7]. This challenge arises because fragment ions from multiple precursors overlap in the mobility dimension. Here, we report the development of a new instrument that combines mobility separations with a linear ion trap device. This combination allows mobility and mass selection of precursor ions. Additionally, multiple stages of tandem mass spectrometry $\left(\mathrm{MS}^{\mathrm{n}}\right)$ can be performed for selected precursor ions. An excimer $\left(\mathrm{F}_{2}\right)$ laser is mounted to the instrument allowing for vacuum ultraviolet photodissociation (VUV PD) experiments leading to the production of unique, diagnostic fragment ions not accessible by CID. The instrument is attractive for the characterization of isomeric species such as those encountered in mixtures of carbohydrate molecules; the drift tube provides a means for ion separation [20, 21] and the different fragmentation techniques can be availed for ion identification.

Here, we describe the instrument and illustrate the approach by analysis of a simple oligosaccharide mixture. Oligosaccharides and carbohydrates perform a wide variety 
of roles in nature. They serve as nutrients or storage units in energy metabolism, play vital roles in molecular recognition, and provide scaffolding for cell walls, connective tissue, and exoskeleton shells [22-24]. Although MS is a powerful diagnostic tool, oligosaccharides present a challenge for MS techniques as they exist in various branched isomer forms [22]. Single-stage tandem mass spectrometry $\left(\mathrm{MS}^{2}\right)$ has been used with some success in confirming structural information associated with single carbohydrate species $[25,26]$. The low-energy fragmentation process of CID is of limited use for these analyses because it primarily produces glycosidic bond cleavages. Multi-stage $\mathrm{MS}^{\mathrm{n}}$ experiments $[27,28]$ are often more effective for carbohydrate analysis. Although isomeric ions tend to form similar $\mathrm{MS}^{2}$ fragments [27], it has been shown that many of these species can be isolated and further fragmented in ways that reveal precursor ion structures. In higher order $\mathrm{MS}^{\mathrm{n}}$, the number of remaining ions begins to introduce limitations. Additionally, this technique requires substantial expertise in the selection of fragment ions for each $\mathrm{MS}^{\mathrm{n}}$ step, as not all fragment ions reveal sufficient structural information to identify ion precursors [28].

Recently, high-energy dissociation techniques have been investigated as a means to provide fragment ions that are more informative leading to a greater ability to distinguish carbohydrate precursor ions [29-32]. Such techniques seek to produce polysaccharide fragment ions through either diagnostic glycosidic cleavages or characteristic cross-ring cleavages of single subunits. VUV PD has been shown to yield intense cross-ring fragmentation of oligosaccharides, which allows for the determination of specific fragmentation pathways $[29,30]$.

In the present work, the capabilities of the new IMS-MS instrument are demonstrated. Melezitose and raffinose, two isomeric trisaccharides, are electrosprayed, separated by IMS, and fragmented using both VUV PD and CID. We note that the current instrumentation is similar to that reported in foundational work that coupled IMS separations with a Paul trap device used to fragment mobility-selected peptide and carbohydrate ions [33]. Exceptions include the addition of photofragmentation capabilities and the pressure regime of the mobility separation. Operation at lower pressures (present work) limit the achievable resolution of the drift tube device due to the use of lower drift voltages, however, such conditions increase the overall signal because ions from the continuous electrospray source can be stored in an ion trapping region prior to each injection into the drift tube. Below, examples of useful applications for the new instrumentation are presented.

\section{Experimental}

\section{Instrumentation Overview}

IMS techniques [34-37] and theory [38-43] as well as the instrumentation utilized to obtain IMS measurements $[2,5,7$, $15,44-56]$ have been described in detail elsewhere. Here, a detailed description of the new instrumentation is provided. Figure 1 shows a schematic of the new IMS-MS instrument. The front half, up to and including the second funnel (F2 in Figure 1), is similar to instruments described elsewhere [34, 38, 40-42]. Briefly, ions from an electrospray ionization (ESI) [57] source are continuously focused through and collected in an hour-glass ion funnel [5] (F1). Periodically the ions are pulsed into the linear drift region that is 0.98 meters long and filled with $\sim 3$ Torr of a buffer gas mixture (see below). Ions traverse the drift region under the influence of a uniform electric field $\left(\sim 2.3 \times 10^{3} \mathrm{~V} \mathrm{~m}^{-1}\right)$ where they separate according to differences in their mobilities through the buffer gas. Ions are then selected by these mobilities using an ion selection gate (Figure 1) and enter a second ion funnel (F2) where they are radially focused to the center axis of the drift tube. Upon exiting the F2 region, ions traverse a short $(\sim 5 \mathrm{~cm})$ drift interface region prior to exiting the drift tube through a conductance limiting $(0.20 \mathrm{~cm})$ aperture. Here the ions enter the LTQ Velos instrument (Thermo Electron, San Jose, CA, USA) where they are directed by rf guides into the higher-pressure linear ion trap. They are subsequently passed to the lower-pressure linear ion trap where they are stored, mass analyzed, and periodically subjected to ion dissociation steps (VUV PD and/or CID).

\section{Recording Ion Mobility Distributions}

Drift time $\left(t_{D}\right)$ distributions are recorded by scanning a delay time that is associated with the application of potentials to the ion introduction and ion selection gates of the instrument. The ion introduction gate consists of a single, gridded lens $(90 \%$ transmittance Ni mesh grid; Precision Eforming, Cortland, NY, USA) located in the exit region of F1. To prevent ions from leaking into the drift region, the potential of this lens is maintained $\sim 40 \mathrm{~V}$ higher than the last lens of F1. The applied voltage on this lens is dropped by $60 \mathrm{~V}$ for $150 \mu \mathrm{s}$ every $18 \mathrm{~ms}$ to allow a pulse of ions to enter the drift region. The application of this voltage is synchronized to a pulsing scheme that is utilized to apply voltages to the ion selection gate. The ion selection gate consists of two-gridded lenses that are spaced apart by $0.32 \mathrm{~cm}$. During the majority of the time, a repulsive field $\left(62.5 \mathrm{~V} \mathrm{~cm}^{-1}\right)$ is maintained between the two lenses. At specified delay times (with respect to the pulse applied to the introduction gate), the field is converted to an attractive field $\left(21.9 \mathrm{~V} \mathrm{~cm}^{-1}\right)$ to allow transmission of mobility selected ions. $t_{D}$ distributions are generated by recording the ion current for each delay time setting. This setting is then scanned across the entire $t_{D}$ range of $\sim 10$ to $\sim 25 \mathrm{~ms}$ using time increments of $\sim 80$ to $150 \mu \mathrm{s}$. The sample introduction pulse and the delay time settings are controlled by two four channel digital/delay pulse generators (Stanford Research Systems, Sunnyvale, CA, USA).

The $t_{D}$ range noted above occurs over a relatively long timescale because the buffer gas used in these studies consists of a mixture of $\mathrm{He}$ and air. For these experiments, $\mathrm{He}$ is leaked into the drift tube directly behind the F2 region (Figure 1). By maintaining a slightly higher pressure in the 


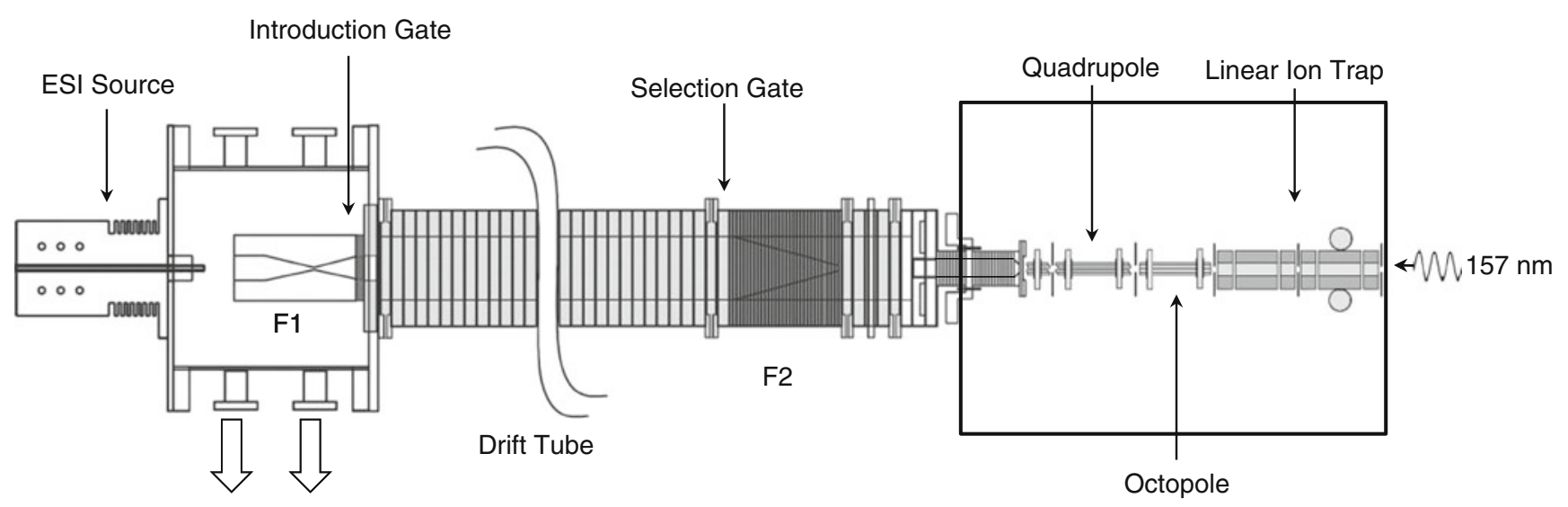

Differential Pumping Region

Figure 1. Schematic of the IMS-MS instrument. The ion source, ion gates, drift tube, and ion trap are labeled. As shown, the laser is aligned with the linear ion trap and can be used to introduce $157 \mathrm{~nm}$ light into the back of the ion trap. Details of the instrument components are discussed in the text

ESI desolvation region, a small amount of gas from the atmospheric source leaks into the drift region. These operating conditions increase the overall sensitivity of the measurements because ions do not have to travel against a gas flow at the drift tube entrance; rather, the gas flow into the drift tube helps to increase the number of ions within each initial pulse. The buffer gas mixture also permits the use of significantly higher fields than drift tubes that utilize 3 Torr of pure He. Usage of a higher drift field increases the overall resolving power of the mobility separation.

\section{Mass Spectrometer Settings and Ion Fragmentation}

The ion trap can be used as a simple mass analyzer to determine the mass to charge ratio $(\mathrm{m} / \mathrm{z})$ of the ions exiting the drift tube. The LTQ Velos is operated without modification to its operating system. To record mass spectra for all ions, the ion gates in the drift tube are turned off and the automatic gain control function of the mass spectrometer is applied. Mass spectra represent a number of integrated scans. Engaging the ion gates inside the drift tube allows the recording of $\mathrm{m} / \mathrm{z}$ distributions for mobility selected-ions. For these datasets, the automatic gain control is turned off and a sample injection time of $8 \mathrm{~s}$ is employed. A two-dimensional, $t_{D}(\mathrm{~m} / \mathrm{z})$ dataset is acquired by collecting such $\mathrm{m} / \mathrm{z}$ distributions for all $t_{D}$ delay settings as described above. For each delay setting, a mass spectrum is recorded for $1 \mathrm{~min}$, leading to a total time of $\sim 1 \mathrm{~h}$ to collect drift time distributions for all species across the $\mathrm{m} / \mathrm{z}$ range employed. The 1-min collection time is somewhat arbitrary and has in part been chosen for these studies because of the current manual data collection process (i.e., each mass spectrum is saved and labeled individually); in the future, automation will allow faster data acquisition rates.

Ions that are stored in the linear trap can be fragmented with CID or VUV PD. The former method is accomplished using the normal operating procedures of the LTQ Velos instrument. Ions are collisionally activated by applying a resonant $\mathrm{rf}$ excitation waveform for $10 \mathrm{~ms}$ with normalized collision energy of $25 \%$ and an activation $\mathrm{q}$ of 0.25 . The instrument has also been modified to accommodate photodissociation experiments by employing a $F_{2}$ laser (EX100HF-60, GAM Laser) as previously described [5860]. The $157 \mathrm{~nm}$ VUV light is introduced at the beginning of the activation step $(10 \mathrm{~ms})$ with the normalized collision energy set to $0 \%$. One hundred fifty scans are integrated for each dataset using an $8 \mathrm{~s}$ injection time resulting in a total data collection time of $\sim 20 \mathrm{~min}$ for VUV PD datasets. The large number of scans is necessary to provide the $S / N$ displayed in these experiments; however, other samples may require additional or fewer scans in order to produce the same data quality. In the data presented here, precursor ions have been mass selected to remove any lower signal ions of similar mobility. Upon mass selection a diagnostic trigger signal is enabled in Tune Plus during the activation stage of mass analysis. The ion trap outputs a $2 \mathrm{~V}$ TTL pulse to a delay generator (555 model; Berkeley Nucleonics Corp., San Rafael, CA, USA), which triggers the laser. To fire the laser during a particular stage of $\mathrm{MS}^{\mathrm{n}}$ the activation diagnostic trigger is enabled in the software. The laser's output energy is approximately $2 \mathrm{~mJ}$ [58].

\section{Sample Preparation}

Melezitose (99\% purity) and raffinose (98\% purity) have been purchased from Sigma-Aldrich (St. Louis, MO, USA) and are used without further purification. Melezitose, raffinose, and a mixture of the two (all at $0.25 \mathrm{mg} / \mathrm{mL}$ ) have been prepared in a water:acetonitrile $(50 \%: 50 \%$ by volume) solution with $2 \mathrm{mM} \mathrm{NaCl}$. The samples are infused through a pulled-tip capillary $(350 \mu \mathrm{m}$ o.d. $\times 75 \mu \mathrm{m}$ i.d. $)$ at a flow rate of $18 \mu \mathrm{L} \cdot \mathrm{h}^{-1}$ using a syringe pump (KD Scientific, Holliston, MA, USA). The solution in the capillary tip is 
biased at $\sim+2000 \mathrm{~V}$ above the potential applied to the instrument entrance aperture to provide $[\mathrm{M}+\mathrm{Na}]^{+}$electrosprayed ions.

\section{Data Analysis}

The data are recorded using the XCalibur 2.1 software suite and processed using software developed in house. To obtain $t_{D}$ and $\mathrm{m} / z$ distributions as well as two-dimensional $t_{D}(\mathrm{~m} / \mathrm{z})$ distributions, the raw data for individual, mobility-resolved $\mathrm{m} / \mathrm{z}$ datasets are compiled into a single three-column array file containing $t_{D}, m / z$, and intensity information. From this file, $t_{D}$ distributions are created by extracting all data points within a narrow $\mathrm{m} / \mathrm{z}$ range centered about the mass associated with the precursor ion of interest. All extracted data points are integrated across the $m / z$ range for each $t_{D}$ bin.

\section{Results and Discussion}

\section{Ion Mobility Distributions for $[\mathrm{M}+\mathrm{Na}]^{+}$Ions}

Melezitose [ $\alpha$-D-Glcp- $(1 \rightarrow 3)-\beta$-D-Fru- $(2 \leftrightarrow 1)-\alpha$-D-Glcp] and raffinose [ $\alpha$-D-Galp- $(1 \rightarrow 6)-\alpha$-D-Glcp- $(1 \leftrightarrow 2)-\beta$-D-Fru] are two isomeric trisaccharides differing only in sequence and linkage. ESI of an equimolar mixture solution (see above) produces a single peak at 527 in the $\mathrm{m} / \mathrm{z}$ distribution corresponding to the $[\mathrm{M}+\mathrm{Na}]^{+}$precursor ions of both isomers. By integrating all points across a narrow $\mathrm{m} / \mathrm{z}$ range ( $\pm 5 \mathrm{Da}$ ), it is possible to generate the $t_{D}$ distribution for the precursor ions as shown in Figure 2. The two peaks associated with the higher- and lower-mobility ions centered at 16.2 and $16.7 \mathrm{~ms}$, respectively, are nearly baseline

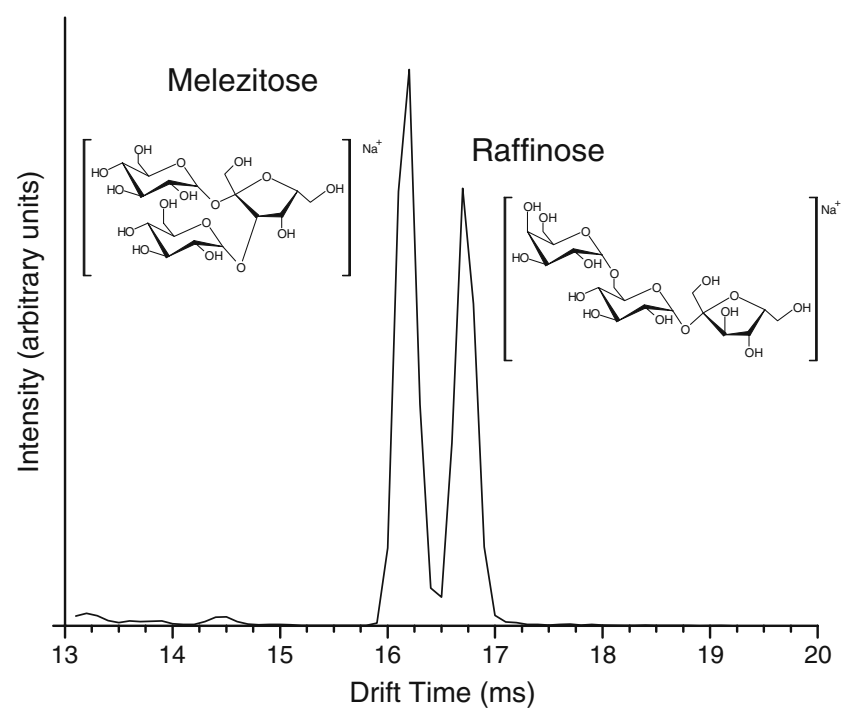

Figure 2. The $t_{D}$ distribution obtained for the analysis of the trisaccharide mixture. The two features in the distribution have been identified by comparisons to analyses of the pure compounds. Labels and schematic representations of the two different isomeric structures are provided for the identified features resolved in the $t_{D}$ distribution. By comparing these times to those obtained from independent analyses of the pure compounds, these respective peaks are assigned to the $[\mathrm{M}+$ $\mathrm{Na}]^{+}$melezitose and raffinose ions.

Theoretically, the two peaks should exhibit Gaussianshaped profiles. The features shown in Figure 2 are pointed at the peak apex. These peak shapes result from an undersampling of the ion populations. For the distribution shown in Figure 2, $t_{D}$ delay settings are spaced $100 \mu$ s apart. At most there are five points (baseline to baseline) across each peak. These settings have been used to collect the samples because significant loss in ion signal is observed at shorter selection times. The cause of this ion loss has not been thoroughly investigated; however, it may result in part from fringing fields that penetrate into the region preceding the ion gate resulting in an ion beam "recovery" time that is on the order of 50 to $100 \mu$ s. Nevertheless, with the peak shapes generated by the mobility separation it is possible to estimate a resolving power $(\mathrm{R})$ for this IMS separation:

$$
R=\frac{t_{D}}{\Delta t}
$$

In Equation (1), $\Delta t$ corresponds to the full width at half maximum (FWHM) of the $t_{D}$ distribution peak. From such an analysis for $[\mathrm{M}+\mathrm{Na}]^{+}$raffinose ions, the resolving power of the instrument is approximately 75 , which is a moderately-high resolution mobility device [5, 20,61-67]. This resolving power is near that $(\sim 70)$ calculated for the transport of a single conformation through the drift tube using the transport equation and an equivalent drift time bin size. The two values agree to within the determination uncertainty.

As a final note, the peak heights of the features in Figure 2 are considered. Assuming similar ionization efficiencies for the two molecules in the mixture, the difference in peak heights may result from factors associated with the measurement. Certainly, increased sampling of the dataset features should provide a more accurate representation of the amount of a given ion. Additionally, it is noted that the collection of this dataset is different from most IMS measurements, where the dispersion of ions on very short timescales allows the collection of distributions in a single experimental sequence. For these data, mobility selections occur over a relatively long timescale and, thus, peak height differences may be reflective of changes in source ESI conditions. Nevertheless, the relatively similar peak heights from such long timescale experiments is encouraging and suggests that quantitative assessments with the approach are possible. Future work will focus on methodologies to derive quantitative information for molecules in complex mixtures using the instrumentation presented here.

\section{Low-Energy CID of Mobility Selected Ions}

Figure 3 shows mass spectra obtained by selecting the two peaks in the $t_{D}$ distribution and subjecting each to 


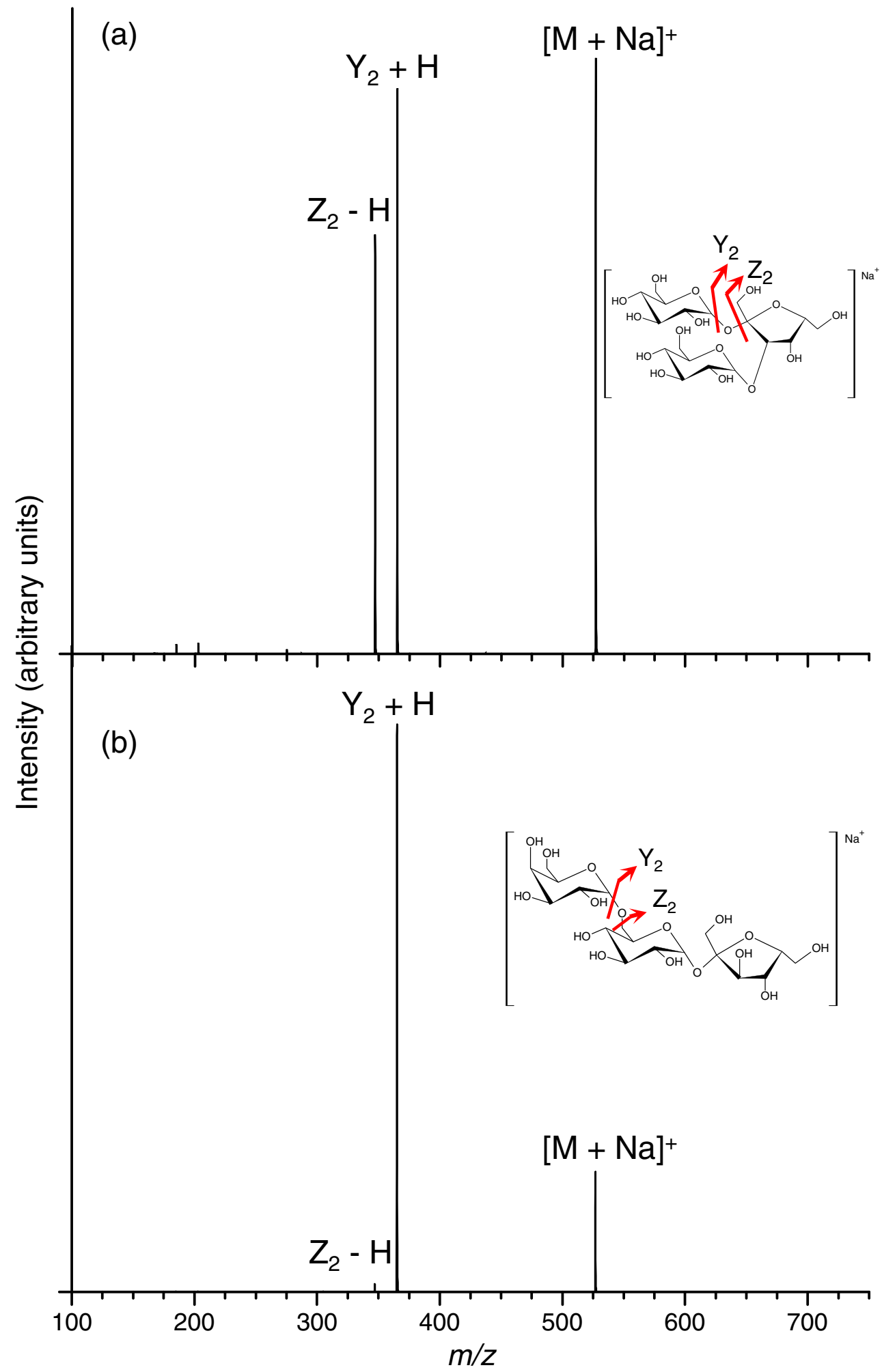

Figure 3. CID spectra of (a) melezitose and (b) raffinose obtained by mobility selection of $[\mathrm{M}+\mathrm{Na}]^{+}$precursor ions from the mixture analysis. Selections have been made at $t_{D}$ values of 16.2 and $16.7 \mathrm{~ms}$, respectively (Figure 2). Major fragment peaks are labeled

energizing collisions in the ion trap. The CID spectrum for $[\mathrm{M}+\mathrm{Na}]^{+}$melezitose ions shows three major peaks at $m / z=527.0,365.1$, and 347.0. These features correspond to the $[\mathrm{M}+\mathrm{Na}]^{+}$precursor ions, loss of a single monosaccharide subunit, and the loss of water from the first fragment ion, respectively. The CID spectrum of [M $+\mathrm{Na}]^{+}$raffinose ions is dominated by two peaks at $\mathrm{m} / \mathrm{z}=$ 527.0 and 365.1. As before, these ions are identified as 
(a)

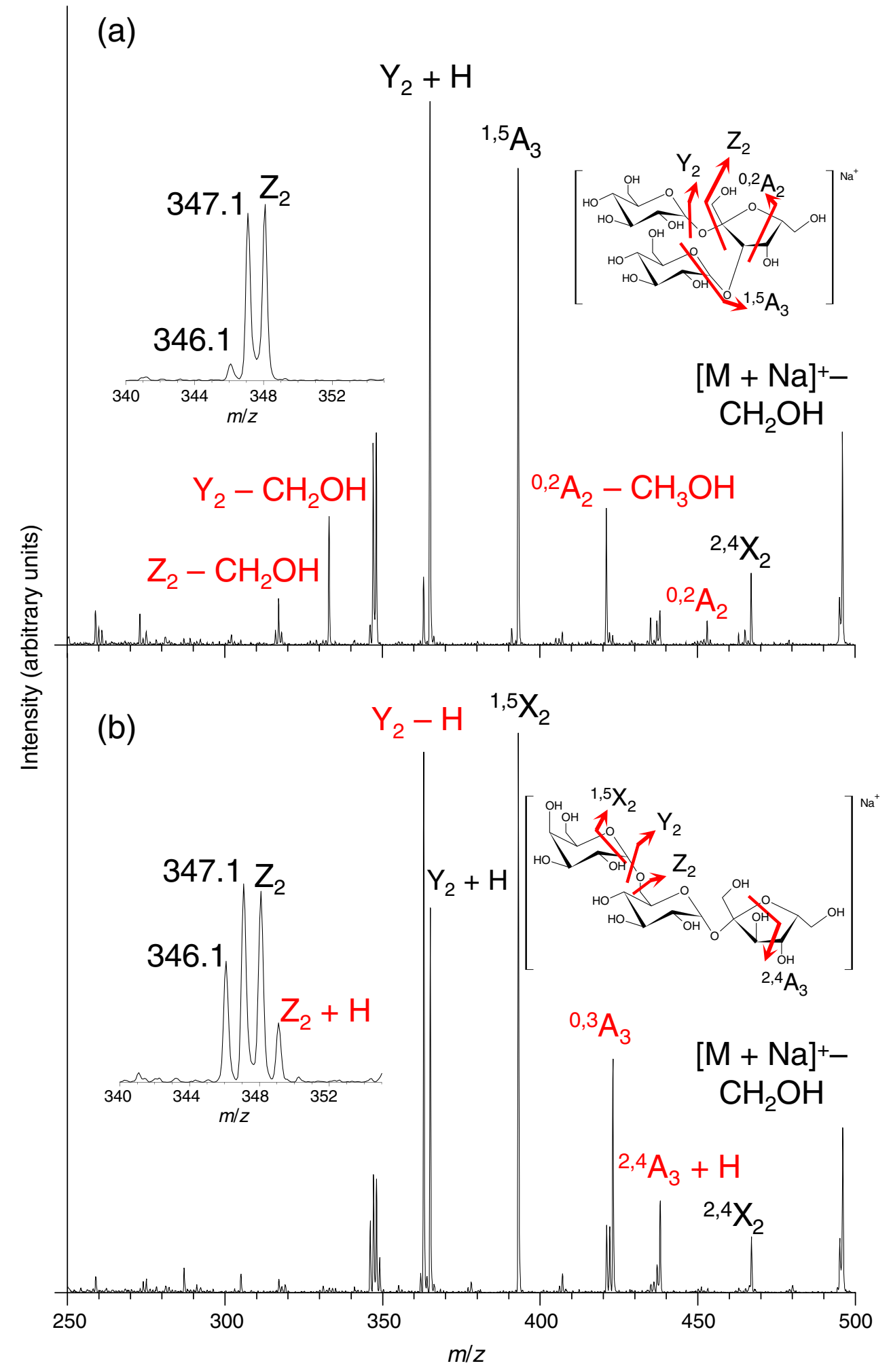

Figure 4. VUV PD spectra of (a) melezitose and (b) raffinose selected from the mixture analysis at $t_{D}$ values of 16.2 and $16.7 \mathrm{~ms}$, respectively (Figure 2). Schematic representations of the two isomers displaying several fragmentation schemes are shown as insets. Separate insets show an expanded $\mathrm{m} / \mathrm{z}$ region (340 to 355 ) to reveal differences in fragmentation patterns. Major fragment ions are assigned with diagnostic fragments shown in red

the precursor ion and the fragment consisting of a single monosaccharide subunit loss. A very small feature corresponding to water loss for the first fragment ion is also evident. It is noteworthy that the CID spectra yield 
different relative intensities for the precursor ions of the two different isomers. Additional experiments as a function of collision energy have shown that the differences in fragmentation patterns are preserved from the onset of fragmentation to higher energy settings. Thus, mobility selection of the precursor ions followed by CID may be used to distinguish, but not characterize these two isomers.

\section{High-Energy VUV PD of Mobility Selected Ions}

Although the CID spectra provide distinguishable patterns for the two precursor ions, very limited structural information is obtained. Previously, it has been shown that VUV PD can produce unique fragment ions for oligosaccharide and $\mathrm{N}$-glycan ions $[29,68]$. The efficacy of VUV PD to produce improved structural information for these ions has also been investigated. Figure 4 shows the VUV PD spectra for [M + $\mathrm{Na}]^{+}$melezitose and raffinose ions. As found in previous studies, substantially more fragment ions are formed by photodissociation. However, because the isomers are composed of the same three monosaccharide units, many of the fragments are common to both species. These include ions with $\mathrm{m} / \mathrm{z}$ values of 348.1, 365.1, 393.1, 467.0, and 496.0. These fragments can be attributed to fragmentation on one of the six-membered rings. As both carbohydrates have this monosaccharide subunit in common, it is likely that the fragment ions are the same in both cases.

Photodissociation of the higher-mobility $[\mathrm{M}+\mathrm{Na}]^{+}$ melezitose ions results in four peaks not produced by fragmentation of raffinose. These fragments appear at $\mathrm{m} / \mathrm{z}$ values of 317.1, 333.1, 421.1, and 453.1. The structures of these fragments have been identified according to conventional carbohydrate nomenclature [69] as the $\mathrm{Z}_{2}-\mathrm{CH}_{2} \mathrm{OH}$, $\mathrm{Y}_{2}-\mathrm{CH}_{2} \mathrm{OH},{ }^{0,2} \mathrm{~A}_{2}-\mathrm{CH}_{3} \mathrm{OH}$, and the ${ }^{0,2} \mathrm{~A}_{2}$ ions, respectively. Similarly, fragment ions with $\mathrm{m} / \mathrm{z}$ values of $349.1,363.1,423.1$, and 438.1 are observed in the photodissociation spectrum of the lower-mobility $[\mathrm{M}+\mathrm{Na}]^{+}$ raffinose ions but not in the spectrum for melezitose precursor ions. These diagnostic fragment ions have been assigned as the $\mathrm{Z}_{2}+\mathrm{H}, \mathrm{Y}_{2}-\mathrm{H},{ }^{0,3} \mathrm{~A}_{3}$, and ${ }^{2,4} \mathrm{~A}_{3}+\mathrm{H}$ species.

\section{Higher Order Tandem MS}

For the carbohydrate sample mixture described in this study, IMS-MS $^{2}$ (with VUV PD) has been sufficient to distinguish the two isomers; however, this may not be the case for more complex systems. In such experiments, IMS-MS ${ }^{\mathrm{n}>2}$ may be required to identify specific sample components. Additionally such an approach may allow experiments to go beyond the generation of a few diagnostic peaks to perform polysaccharide de novo sequencing. The instrument described here has the capability to perform $\mathrm{MS}^{10}$ experiments and can substitute one of the CID steps with VUV PD. To demonstrate higher-order tandem MS, CID has been performed on the $\mathrm{Y}_{2}-\mathrm{H}$ fragment ion produced by photodissociation of the mobility-selected $[\mathrm{M}+\mathrm{Na}]^{+}$

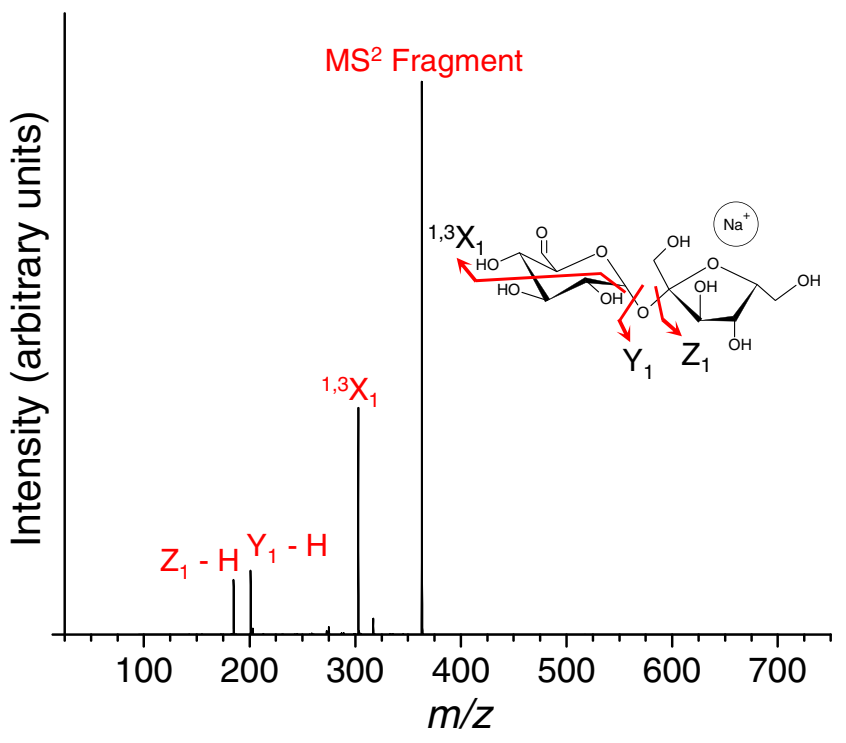

Figure 5. $\mathrm{A} \mathrm{MS}^{3}$ spectrum produced by $\mathrm{CID}$ of the $363.0 \mathrm{Da}$ fragment ion produced by photodissociation of mobilityselected $[\mathrm{M}+\mathrm{Na}]^{+}$raffinose ions. Resulting CID fragment ions are labeled on the mass spectrum. The inset shows the structure of the photofragment and proposed cleavages producing the CID fragments

raffinose ion precursor. In the $\mathrm{MS}^{3}$ spectrum (Figure 5), three dominant fragment ions are produced upon collisional activation. These include the ${ }^{1,3} \mathrm{X}_{1}, \mathrm{Y}_{1}-\mathrm{H}$, and $\mathrm{Z}_{1}-\mathrm{H}$ ions at $m / z$ values of 303.0, 201.0, and 184.9, respectively.

\section{Applications of the New Instrumentation}

The new IMS-ion trap instrument described here is extremely versatile and should find utility in the analysis of a number of different samples. Of particular interest are mixtures that contain isobaric species. The recent applications of IMS separations in the characterization of glycan isomers $[16,17]$, suggests that the new approach should be useful in characterizing structures of these species. For such studies, the combination of mobility separation with VUV PD and subsequent CID is attractive because it provides the greatest opportunity to obtain corroborative fragments for mixture component identification. Another potential application is in the field of petroleomics. IMS-MS studies have shown that many isobaric species are not fully resolved in the IMS domain [70, 71]. However, the generation of diagnostic fragments that are coincident in $t_{D}$ with precursor ions may allow the separation of specific ions including those with overlapping mobilities. Additionally, the instrumentation can be used to pinpoint sites of post-translational modification (PTM) as well as to determine specific collision cross sections for peptide ions containing PTMs. Finally it is noteworthy to consider the incorporation of multidimensional IMS (IMS ${ }^{\mathrm{n}}$ ) techniques [20, 64]. Straightforward modification of the drift tube would allow the insertion of ion activation regions that can be used to 
fragment precursor ions or induce structural transformations. Such an instrument would allow the characterization of mobility-separated fragment ions or new ion conformations.

\section{Summary}

A new instrument that combines IMS separations, ion trapping, and ion fragmentation techniques has been described. A particularly novel aspect of the new instrumentation is the use of VUV PD to produce unique fragment ions for specific, mobility-separated precursor ions. The method has been illustrated by characterizing the ions formed by electrospraying a mixture of the isomeric trisaccharides melezitose and raffinose. Currently, the ability to perform VUV PD and CID in $\mathrm{MS}^{\mathrm{n}}$ experiments is limited only by the number of available ions suggesting that in the future many species may be characterized extensively to determine precursor ion structures. Thus, the technology described here shows significant promise for analyzing complex mixtures of geometric isomers.

\section{Acknowledgments}

The authors acknowledge financial support by the NIH (1RC1GM090798-01). They are also grateful for the support of the Indiana University Mechanical and Electrical Instrumentation Services facilities.

\section{References}

1. Hoaglund, C.S., Valentine, S.J., Sporleder, C.R., Reilly, J.P., Clemmer, D.E.: Three-Dimensional Ion Mobility/TOFMS Analysis of Electrosprayed Biomolecules. Anal. Chem. 70, 2236-2242 (1998)

2. Gillig, K.J., Ruotolo, B., Stone, E.G., Russell, D.H., Fuhrer, K., Gonin, M., Schultz, A.J.: Coupling High-Pressure MALDI with Ion Mobility/ Orthogonal Time-of-Flight Mass Spectrometry. Anal. Chem. 72, 3965$3971(2000)$

3. Thalassinos, K., Slade, S.E., Jennings, K.R., Scrivens, J.H., Giles, K., Wildgoose, J., Hoyes, J., Bateman, R.H., Bowers, M.T.: Ion Mobility Mass Spectrometry of Proteins in a Modified Commercial Mass Spectrometer. Int. J. Mass Spectrom. 236, 55-63 (2004)

4. Clowers, B.H., Dwivedi, P., Steiner, W.E., Bendiak Hill, B., Hill, H.H.: Separation of Sodiated Isobaric Disaccharides and Trisaccharides Using Electrospray Ionization-Atmospheric Pressure Ion Mobility-Time of Flight Mass Spectrometry. J. Am. Soc. Mass Spectrom. 16, 660-669 (2005)

5. Tang, K., Shvartsburg, A.A., Lee, H., Prior, D.C., Buschbach, M.A., Li, F., Tomachev, A., Anderson, G.A., Smith, R.D.: High-Sensitivity Ion Mobility Spectrometry/Mass Spectrometry Using Electrodynamic Ion Funnel Interfaces. Anal. Chem. 77, 3330-3339 (2005)

6. Fenn, L.S., McLean, J.A.: Biomolecular Structural Separations by Ion Mobility-Mass Spectrometry. Anal. Bioanal. Chem. 391, 905-909 (2008)

7. Hoaglund-Hyzer, C.S., Li, J., Clemmer, D.E.: Mobility Labeling for Parallel CID of Ion Mixtures. Anal. Chem. 72, 2737-2740 (2000)

8. Stone, E., Gillig, K.J., Ruotolo, B., Fuhrer, K., Gonin, M., Schultz, A., Russell, D.H.: Surface-Induced Dissociation on a MALDI-ion MobilityOrthogonal Time-of-Flight Mass Spectrometer: Sequencing peptides from an "in-solution" protein digest. Anal. Chem. 73, 2233-2238 (2001)

9. Lee, Y.J., Hoaglund-Hyzer, C.S., Taraszka, J.A., Zientara, G.A., Counterman, A.E., Clemmer, D.E.: Collision-Induced Dissociation of Mobility-Separated Ions Using an Orifice-Skimmer Cone at the Back of a Drift Tube. Anal. Chem. 73, 3549-3555 (2001)

10. Valentine, S.J., Koeniger, S.L., Clemmer, D.E.: A Split-field Drift Tube for Separation and Efficient Fragmentation of Biomolecular Ions. Anal. Chem. 75, 6202-6208 (2003)
11. Valentine, S.J., Plasencia, M.D., Liu, X., Krishnan, M., Naylor, S., Udseth, H.R., Smith, R.D., Clemmer, D.E.: Toward Plasma Proteome Profiling with Ion Mobility-Mass Spectrometry. J. Proteome Res. 5, 2977-2984 (2006)

12. Myung, S., Lee, Y.L., Moon, M.H., Taraszka, J.A., Sowell, R., Koeniger, S.L., Hilderbrand, A.E., Valentine, S.J., Cherbas, L., Cherbas, P., Kaufmann, T.C., Miller, D.F., Mechref, Y., Novotny, M. V., Ewing, M., Clemmer, D.E.: Development of High-Sensitivity Ion Trap Ion Mobility Spectrometry Time-of-Flight Techniques: A HighThroughput Nano-LC-IMS-TOF Separation of Peptides Arising from a Drosophila Protein Extract. Anal. Chem. 75, 5137-5145 (2003)

13. Taraszka, J.A., Gao, X., Valentine, S.J., Sowell, R.A., Koeniger, S.L., Miller, D.F., Kaufman, T.C., Clemmer, D.E.: Proteome Profiling for Assessing Diversity: Analysis of Individual Heads of Drosophila melanogaster Using LC-Ion Mobility-MS. J. Proteome Res. 4, 12381247 (2005)

14. Liu, X., Valentine, S.J., Plasencia, M.D., Trimpin, S., Naylor, S., Clemmer, D.E.: Mapping the Human Plasma Proteome by SCX-LCIMS-MS. J. Am. Soc. Mass Spectrom. 18, 1249-1264 (2007)

15. Belov, M.E., Clowers, B.H., Prior, D.C., Danielson, W.F., Liyu, A.V., Petritis, B.O., Smith, R.D.: Dynamically multiplexed ion mobility timeof-flight mass spectrometry. Anal. Chem. 80, 5873-5883 (2008)

16. Isailovic, D., Kurulugama, R.T., Plasencia, M.D., Stokes, S.T., Kyselova, Z., Goldman, R., Mechref, Y., Novotny, M.V., Clemmer, D.E.: Profiling of Human Serum Glycans Associated with Liver Cancer and Cirrhosis by IMS-MS. J. Proteome Res. 7(3), 1109-1117 (2008)

17. Plasencia, M.D., Isailovic, D., Merenbloom, S.I., Mechref, Y., Clemmer, D.E.: Resolving and Assigning N-linked Glycan Structural Isomers from Ovalbumin by IMS-MS. J. Am. Soc. Mass Spectrom. 19 (11), 1706-1715 (2008)

18. Dwivedi, P., Wu, P., Klopsch, S.J., Puzon, G.J., Xun, L., Hill, H.H.: Metabolic Profiling by Ion Mobility Mass Spectrometry (IMMS). Metabolomics 4, 63-80 (2008)

19. Dwivedi, P., Schultz, A.J., Hill, H.H.: Metabolic Profiling of Human Blood by High-Resolution Ion Mobility Mass Spectrometry (IM-MS). Int. J. Mass Spectrom. 298, 78-90 (2010)

20. Koeniger, S.L., Merenbloom, S.I., Valentine, S.J., Jarrold, M.F., Udseth, H.R., Smith, R.D., Clemmer, D.E.: An IMS-MS Analogue of MS-MS. Anal. Chem. 78(12), 4161-4174 (2006)

21. Liu, Y., Clemmer, D.E.: Characterizing Oligosaccharides Using Injectedion Mobility/Mass Spectrometry. Anal. Chem. 69, 2504-2509 (1997)

22. Boyer, R.: Concepts in Biochemistry. Wiley, New York (2002)

23. Crocker, P.R., Feizi, T.: Carbohydrate Recognition Systems: Functional Triads in Cell-Cell Interactions. Glycoconj. J. 6, 679-691 (1996)

24. Latgé, J.P.: The Cell Wall: A Carbohydrate Armor for the Fungal Cell. Mol. Microbiol. 66, 279-290 (2007)

25. Sheely, D.M., Reinhold, V.N.: Structural Characterization of Carbohydrate Sequence, Linkage, and Branching in a Quadrupole Ion Trap Mass Spectrometer: Neutral Oligosaccharides and N-Linked Glycans. Anal. Chem. 70, 3053-3059 (1998)

26. Weiskopf, A.S., Vouros, P., Harvey, D.J.: Electrospray Ionization-Ion Trap Mass Spectrometry for Structural Analysis of Complex N-Linked Glycoprotein Oligiosaccharides. Anal. Chem. 70, 4441-4447 (1998)

27. Ashline, D.J., Singh, S., Hanneman, A., Reinhold, V.R.: Congruent Strategies for Carbohydrate Sequencing. 1. Mining Structural Details by MS $^{n}$. Anal. Chem. 77, 6250-6262 (2005)

28. Ashline, D.J., Lapadula, A.J., Liu, Y., Lin, M., Grace, M., Pramanik, B., Reinhold, V.R.: Carbohydrate Structural Isomers Analyzed by Sequential Mass Spectrometry. Anal. Chem. 79, 3830-3842 (2007)

29. Devakumar, A., Thompson, M.S., Reilly, J.P.: Fragmentation of Oligosaccharide Ions with $157 \mathrm{~nm}$ Vacuum Ultraviolet Light. Rapid Comm. Mass Spectrom. 19, 2313-2320 (2005)

30. Spina, E.S.L., Romeo, D., Impallomeni, G., Garozzo, D., Waidelich, D., Glueckmann, M.: New Fragmentation Mechanisms in Matrix-Assisted Laser Desorption/Ionization Time-of-Flight Tandem Mass Spectrometry of Carbohydrates. Rapid Commun. Mass Spectrom. 18, 392-398 (2004)

31. Mechref, Y., Novotny, M.V., Krishnan, C.: Structural Characterization of Oligosaccharides Using MALDI-TOF/TOF Tandem Mass Spectrometry. Anal. Chem. 75, 4895-4903 (2003)

32. Morelle, W., Slomianny, M.C., Diemer, H., Schaeffer, C., van Dorsselaer, A., Michalski, J.C.: Fragmentation Characteristics of Permethylated Oligosaccharides Using a Matrix-Assisted Laser Desorption/Ionization Two-Stage Time-of-Flight (TOF/TOF) Tandem Mass Spectrometer. Rapid Commun. Mass Spectrom. 18, 2637-2649 (2004) 
33. Clowers, B.H., Hill Jr., H.H.: Mass Analysis of Mobility-Selected Ion Populations Using Dual-Gate, Ion Mobility, Quadrupole Ion Trap Mass Spectrometry. Anal. Chem. 77, 5877-5885 (2005)

34. Mason, E.A., McDaniel, E.W.: Transport Properties of Ions in Gases. Wiley, New York (1988)

35. Clemmer, D.E., Jarrold, M.F.: Ion Mobility Measurements and their Applications to Clusters and Biomolecules. J. Mass Spectrom. 32, 577592 (1997)

36. For a review of IMS techniques (and references therein) see: St. Louis, R. H.; Hill, H. H. Ion Mobility Spectrometry in Analytical Chemistry. Crit. Rev. Anal. Chem. 21, 321-355 (1990)

37. For a review of IMS techniques (and references therein) see: Hoaglund Hyzer, C. S.; Counterman, A. E.; Clemmer, D. E. Anhydrous Protein Ions. Chem. Rev. 99, 3037-3079 (1999)

38. Revercomb, H.E., Mason, E.A.: Theory of Plasma Chromatography Gaseous Electrophoresis. Anal. Chem. 47, 970-983 (1975)

39. Mack, E.: Average Cross-Sectional Areas of Molecules by Gaseous Diffusion Methods. J. Am. Chem. Soc. 47, 2468-2482 (1925)

40. Shvartsburg, A.A., Jarrold, M.F.: An Exact Hard-Spheres Scattering Model for the Mobilities of Polyatomic Ions. Chem. Phys. Lett. 261, 86-91 (1996)

41. Mesleh, M.F., Hunter, J.M., Shvartsburg, A.A., Schatz, G.C., Jarrold, M.F.: Structural Information from Ion Mobility Measurements: Effects of Long-range Potential. J. Phys. Chem. 100, 16082-16086 (1996)

42. Wyttenbach, T., von Helden, G., Batka, J.J., Carlat, D., Bowers, M.T.: Effect of the Long-Range Potential on Ion Mobility Measurements. $J$. Am. Soc. Mass Spectrom. 8, 275-282 (1997)

43. Shvartsburg, A.A., Hudgins, R.R., Dugourd, P., Jarrold, M.F.: Structural Information from Ion Mobility Measurements: Applications to Semiconductor Clusters. Chem. Soc. Rev. 30, 26-35 (2001)

44. Myung, S., Badman, E.R., Lee, Y.J., Clemmer, D.E.: Structural Transitions of Electrosprayed Ubiquitin Ions Stored in an Ion Trap over $10 \mathrm{~ms}$ to 30 s. J. Phys. Chem. A 106, 9976-9982 (2002)

45. Ruotolo, B.T., Gillig, K.J., Stone, E.G., Russell, D.H.: Peak Capacity of Ion Mobility Mass Spectrometry: Separation of Peptides in Helium Buffer Gas. J. Chromatogr. B 782, 385-392 (2002)

46. Wittmer, D., Luckenbill, B.K., Hill, H.H., Chen, Y.H.: ElectrosprayIonization Ion Mobility Spectrometry. Anal. Chem. 66, 2348-2355 (1994)

47. Clemmer, D.E., Hudgins, R.R., Jarrold, M.F.: Naked Protein Conformations: Cytochrome $c$ in the Gas Phase. J. Am. Chem. Soc. 117, 10141-10142 (1995)

48. von Helden, G., Wyttenbach, T., Bowers, M.T.: Conformation of Macromolecules in the Gas Phase: Use of Matrix-Assisted Laser Desorption Methods in Ion Chromatography. Science 267, 1483-1485 (1995)

49. von Helden, G., Wyttenbach, T., Bowers, M.T.: Inclusion of a MALDI Ion Source in the Ion Chromatography Technique: Conformational Information on Polymer and Biomolecular Ions. Int. J. Mass Spectrom. Ion Processes 146, 349-364 (1995)

50. Chen, Y.H., Siems, W.F., Hill Jr., H.H.: Fourier Transform Electrospray Ion Mobility Spectrometry. Anal. Chim. Acta 334(1/2), 75-84 (1996)

51. Bluhm, B.K., Gillig, K.J., Russell, D.H.: Development of a FourierTransform Ion Cyclotron Resonance Mass Spectrometer-Ion Mobility Spectrometer. Rev. Sci. Instrum. 71(11), 4078-4086 (2000)

52. Hoaglund-Hyzer, C.S., Clemmer, D.E.: Ion Trap/Ion Mobility/Quadrupole/Time-of-Flight Mass Spectrometry for Peptide Mixture Analysis. Anal. Chem. 73, 177-184 (2001)
53. Counterman, A.E., Clemmer, D.E.: Large Anhydrous Polyalanine Ions: Evidence for Extended Helices and Onset of a More Compact Structure. J. Am. Chem. Soc. 123, 1490-1498 (2001)

54. Clowers, B.H., Siems, W.F., Hill, H.H., Massick, S.M.: Hadamard Transform Ion Mobility Spectrometry. Anal. Chem. 78, 44-51 (2006)

55. Sun, W.J., May, J.C., Russell, D.H.: A Novel Surface-Induced Dissociation Instrument for Ion Mobility-Time-of-Flight Mass Spectrometry. Int. J. Mass Spectrom. 259, 79-86 (2007)

56. Baker, E.S., Tang, K.Q., Danielson, W.F.I.I.I., Prior, D.C., Smith, R.D.: Simultaneous Fragmentation of Multiple Ions Using IMS Drift Time Dependent Collision Energies. J. Am. Soc. Mass Spectrom. 19(3), 411419 (2008)

57. Fenn, J.B., Mann, M., Meng, C.K., Wong, S.F., Whitehouse, C.M.: Electrospray Ionization for Mass Spectrometry of Large Biomolecules. Science 246, 64 (1989)

58. Kim, T., Valentine, S.J., Clemmer, D.E., Reilly, J.P.: Gas-Phase Conformation-Specific Photofragmentation of Proline-Containing Peptide Ions. J. Am. Soc. Mass Spectrom. 21, 1455-1465 (2010)

59. Devakumar, A., Mechref, Y., Kang, P., Novotny, M.V., Reilly, J.P.: Laser-induced Photofragmentation of Neutral and Acidic Glycans Inside an Ion-trap Mass Spectrometer. Rapid Commun. Mass Spectrom. 21(8), 1452-1460 (2007)

60. Kim, T., Thompson, M.S., Reilly, J.P.: Peptide photodissociation at $157 \mathrm{~nm}$ in a Linear Ion Trap Mass Spectrometer. Rapid Commun. Mass Spectrom. 19, 1657-1665 (2005)

61. Dugourd, Ph, Hudgins, R.R., Clemmer, D.E., Jarrold, M.F.: HighResolution Ion Mobility Measurements. Rev. Sci. Instrum. 68, 11221129 (1997)

62. Wu, C., Siems, W.F., Asbury, G.R., Hill, H.H.: Electrospray Ionization High-Resolution Ion Mobility Spectrometry-Mass Spectrometry. Anal. Chem. 70, 4929-4938 (1998)

63. Asbury, G.R., Hill, H.H.: Evaluation of ultrahigh resolution ion mobility spectrometry as an analytical separation device in chromatographic terms. J. Microcolumn Sep. 12, 172-178 (2000)

64. Merenbloom, S.I., Koeniger, S.L., Valentine, S.J., Plasencia, M.D., Clemmer, D.E.: IMS-IMS and IMS-IMS-IMS/MS for Separating Peptide and Protein Fragment Ions. Anal. Chem. 78, 2802-2809 (2006)

65. Gillig, K.J., Ruotolo, B.T., Stone, E.G., Russell, D.H.: An Electrostatic Focusing Ion Guide for Ion Mobility-Mass Spectrometry. Int. J. Mass Spectrom 239, 43-49 (2004)

66. Kemper, P.R., Dupuis, N.F., Bowers, M.T.: A New, Higher Resolution, Ion Mobility Mass Spectrometer. Int. J. Mass Spectrom. 287, 46-57 (2009)

67. Srebalus, C.A., Li, J., Marshall, W.S., Clemmer, D.E.: Gas Phase Separations of Electrosprayed Peptide Libraries. Anal. Chem. 71, 39183927 (1999)

68. Devakumar, A., Mechref, Y., Kang, P., Novotny, M.V., Reilly, J.P.: Identification of Isomeric N-Glycan Structures by Mass Spectrometry with $157 \mathrm{~nm}$ Laser-Induced Photofragmentation. J. Am. Soc. Mass Spectrom. 19, 1027-1040 (2008)

69. Domon, B., Costello, C.E.: A Systematic Nomenclature for Carbohydrate Fragmentations in FAB-MS MS Spectra of Glycoconjugates. Glycoconj. J. 5, 397-409 (1988)

70. Fernandez-Lima, F.A., Becker, C., McKenna, A.M., Rodgers, R.P., Marshall, A.G., Russell, D.H.: Petroleum Crude Oil Characterization by IMS-MS and FTICR MS. Anal. Chem. 81, 9941-9947 (2009)

71. Li, Z.; Stephen, V. J.; Clemmer, D. E. Complexation of Amino Compounds by 18 C6 Improves Selectivity by IMS-IMS-MS: Application to Petroleum Characterization. Anal. Chem. 22, 817-827 (2011) 